\title{
Neuropathic ulcer: rare manifestation of Eosinophilic granulomatosis with polyangiitis
}

\author{
P. Thineskaran, S. Pirasath, G. Selvaratnam,V. Perera. \\ Teaching Hospital Jaffna, Sri Lanka.
}

Keywords: Eosinophilic granulomatosis; polyangiitis; neuropathic ulcer

\section{Introduction}

Eosinophilic granulomatosis with polyangiitis (EGPA) is a small vessel, multisystem vasculitis associated with refractory bronchial asthma, eosinophilia, peripheral neuropathy and lung infiltrates. We report a case of EGPA presenting with bronchial asthma, non-healing neuropathic ulcer with polyneuropathy, eosinophilia, pulmonary infiltrates and eosinophilic tissue infiltrates on biopsy.

\section{Case presentation}

A 15-year-old girl presented with recurrent ulcer with sensory impairment on left hand for 6 months duration. She had progressive nodular skin lesions on left third finger for 8 months duration. She had poorly controlled childhood bronchial asthma since the age of 5 years. She had three lifethreatening episodes, which was managed in the intensive care unit. She had bilateral polyphonic rhonchi on examination. She had an ulcer with sensory impairment on the extensor surface of the left hand with ulnar claw hand (Figure 1). Her complete blood count showed eosinophilia (6.3\%) with normal other cell counts. Her inflammatory markers, liver and renal function were normal (CRP-1.9mg/L and ESR-n $26 \mathrm{~mm} / 1$ st hour). Her chest x-ray showed patchy opacities in the upper zones of both lungs. The patchy ground glass appearance was noted in high resolution of computed tomography. The skin punch biopsy showed necrotizing vasculitis, tissue eosinophilia and extravascular granulomata suggestive of EGPA. Her vasculitic screening (C-ANCA and P-ANCA) were negative. Her diagnosis was EGPA and she was managed with corticosteroids. She improved with therapy and was followed up at a medical clinic.

\section{Discussion}

EGPA is manifested by the late onset of asthma, and eosinophilic vasculitis of small- and medium-sized vessels [1]. It is defined as an eosinophil-rich and necrotizing

Correspondence: Selladurai Pirasath

E-mail: selladuraipirasath81@gmail.com

Received: 01-12-2018 Accepted: 21-12-2018

(iD http://orcid.org/0000-0002-4274-4919

DOI: http://doi.org/10.4038/sljs.v36i4.8561

The Sri Lanka Journal of Surgery 2018; 36(4): 42-43
The lesion was plastered with $6 \mathrm{~mm}$ balloon and the symptom resolved immediately and she was discharged home on the same day and no immediate issue was observed during her dialysis.

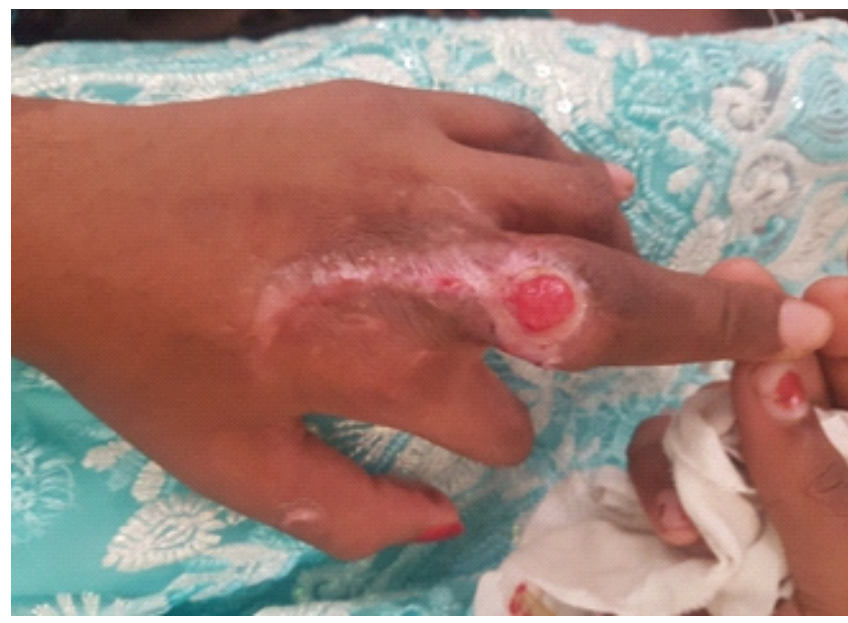

Figure 1. The poorly healing ulcer with sensory impairment on the extensor surface of left hand with ulnar

granulomatous inflammation [2], and necrotizing vasculitis associated with asthma and eosinophilia [3] according to the 2012 revised International Chapel Hill Consensus Conference Nomenclature of Vasculitides.

Our patient had asthma, peripheral eosinophilia, polyneuropathy, pulmonary infiltrates and eosinophilic tissue infiltrates, fulfilling the American College of Rheumatology criteria for EGPA [4]. The p-ANCA is positive among 40-60 $\%$ of patients with EGPA [5]. It was negative in our patient. The necrotizing vasculitis with eosinophilic infiltration in the vessels is the histopathological feature. Our patient had a histological feature of EGPA. The electrodiagnostic study showed confluent sensory-motor axonal mononeuropathy multiplex. Lung computed tomography (CT) scan showed patchy ground-glass opacity with a mosaic pattern. HRCT of our patient also suggestive for diagnosis of EGPA. Rapid diagnosis is necessary for management of ANCA-associated vasculitis and early initiation of immunosuppressants is mandatory for good clinical outcome [6]. She improved with systemic corticosteroids promptly and her wound healed completely and she did not have any exacerbations of bronchial asthma for last one year. 
This case highlights that a common surgical presentation of a much less common systemic disease. Surgeons should be aware that nonhealing ulcer is the neurological manifestations of EGPA. Unhealing ulcer with marked peripheral eosinophilia, especially in patients with refractory asthma, should alert the clinician to the possibility of this rare disorder of EGPA.

All authors disclose no conflict of interest. The study was conducted in accordance with the ethical standards of the relevant institutional or national ethics committee and the Helsinki Declaration of 1975 , as revised in 2000 .

\section{References}

1. Greco A, Rizzo MI, De Virgilio A, Gallo A, Fusconi M, et al. Churg-Strauss syndrome. Autoimmun Rev 2015; 14: 341-8. https://doi.org/10.1016/j.autrev.2014.12.004

2. Marques CC, Fernandes EL, Miquelin GM, Colferai MM. Cutaneous manifestations of Churg-Strauss syndrome: key to diagnosis. An Bras Dermatol 2017; 92(5 Suppl 1):56-8.
3. Jennette JC, Falk RJ, Bacon PA, Basu N, Cid MC, et al. 2012 revised International Chapel Hill Consensus Conference Nomenclature of Vasculitides. Arthritis Rheum 2013;65: 1-11. https://doi.org/10.1002/art.37715

4. Masi AT, Hunder GG, Lie JT, Michel BA, Bloch DA, Arend WP et al. The American College of Rheumatology 1990 criteria for the classification of Churg-Strauss syndrome (allergic granulomatosis and angiitis). Arthritis Rheum 1990 ; 33(8):1094-100. https://doi.org/10.1002/art.1780330806

5. Villacorta J, Díaz - Crespo F, Stanescu R, Fernandez - Juarez G.Large and small vessel severe involvement in ANCAassociated vasculitis. J Vasc; 2: e105.

6. E. Ntatsaki, D. Carruthers, K. Chakravarty et al., "BSR and BHPR guideline for the management of adults with ANCA-associated vasculitis,". Rheumatology, 2014;53 (12): 2306-9. https://www.ncbi.nlm.nih.gov/pubmed/24729399. https://doi.org/10.1093/rheumatology/ket445

\section{Learning Points:}

- Non healing ulcer with marked peripheral eosinophilia, especially in patients with refractory asthma, should alert the surgeons to the possibility of this rare disorder of EGPA. 